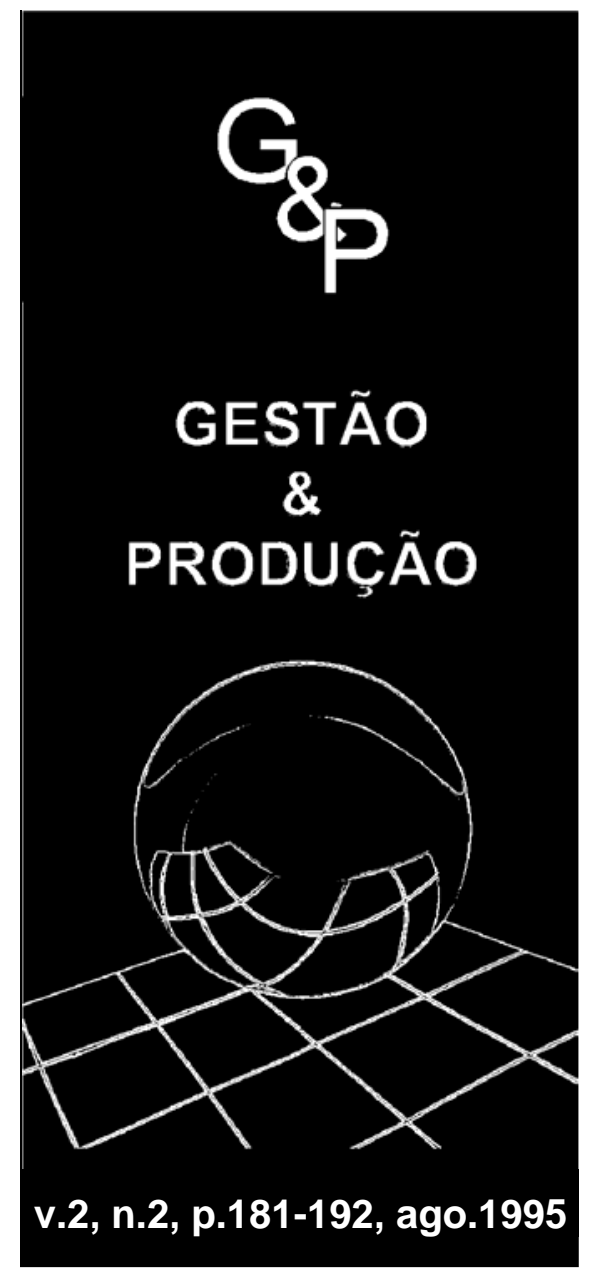

\title{
IMPACTOS DA TECNOLOGIA DE INFORMAÇÃO SOBRE O TRABALHO DE "COLARINHO BRANCO"
}

\author{
Paulo César Simões Borges \\ Doutorando em Engenharia de Produção \\ da Escola Politécnica da USP \\ IBM Brasil Ltda.- Centro Industrial: \\ fone: 0192-65.7000; fax: 0192-65.7591
} Caixa Postal 71, CEP 13.001-970 - Campinas, SP

\section{Resumo}

Grandes investimentos em tecnologia de informação (TI) vêm sendo canalizados para a melhoria dos processos empresariais. Esses investimentos limitam-se, em geral, à automação pura e simples dos processos já existentes na companhia, os quais continuam sendo realizados pelos mesmos profissionais e regidos pelos mesmos princípios anteriores à TI. Um corolário deste tipo de automação é o pequeno ganho de produtividade do trabalho de colarinho branco. Uma alternativa para este problema é a reengenharia de processos, que por meio do uso criativo da TI e da gestão por processos procura estabelecer novas formas muito mais eficientes de realizar o trabalho. Entretanto, tais formas alteram, freqüente $e$ fundamentalmente, o perfil do profissional e a natureza de seu trabalho. É sobre estes impactos que estaremos discorrendo ao longo deste artigo.

\section{Palavras-chave: tecnologia de informação, trabalho administrativo, organização do trabalho, reengenharia, processos empresariais.}

\section{Introdução}

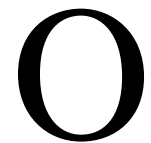

objetivo deste trabalho é estudar os impactos das recentes tecnologias de informação sobre o trabalho humano não diretamente ligado à manufatura - conhecido como trabalho de "colarinho branco" - dentro do contexto da empresa industrial. Desenvolvimento de novos produtos, desenvolvimento de sistemas e serviços de informação, aquisição de mate-riais, planejamento financeiro, 
GESTÃO \& PRODUÇÃO V.2, n.2, p. 181- 192, ago. 1995

faturamento, 
atendimento e serviço ao cliente, recrutamento e orientação de funcionários, desenvolvimento de mercados e novos negócios, distribuição de produtos, gerência de materiais, etc. são exemplos característicos de processos empresariais nos quais este tipo de trabalho é realizado.

Adotando uma perspectiva sócio-técnica, podemos caracterizar a empresa - um tipo particular de organização com fins lucrativos - como constituída por dois subsistemas: o subsistema técnico - composto por máquinas, equipamentos, tecnologia, etc. - e o subsistema social - formado por indivíduos, grupos de indivíduos, seus comportamentos, capacidades, cultura, etc. (BIAZZI, 1994). Estes dois subsistemas interagem entre si, sendo que avanços alternados em cada subsistema têm proporcionado o desenvolvimento industrial (BURNS, 1963).

A empresa também interage com o ambiente externo, ou seja, é um sistema aberto. O ambiente pode ser definido como tudo que está "fora" do sistema empresa, sendo que, quando muito, ela pode influenciá-lo. Entretanto, o ambiente determina, em parte, o funcionamento do sistema (CHURCHMAN, 1972). Fatores como clientes, fornecedores, concorrentes, instituições diversas, conhe- cimento científico e tecnológico, sociedade, conjuntura político-econômica e governo podem ser considerados constituintes do ambiente de uma empresa.

Este ambiente tem características dinâmicas, com constantes alterações em seu estado. Tais alterações no ambiente fazem com que as empresas manifestem reações (no próprio sistema empresa e/ou no ambiente) visando a adaptação às novas situações. Desta forma, uma empresa é, também, um sistema adaptativo ao ambiente. Assim sendo, é de grande importância o interrelacionamento do ambiente externo com as adaptações e inovações nos subsistemas técnico e social das empresas.

Baseando-nos em BURNS (1963), expomos que o entendimento (sob o prisma sistêmico) da evolução do interrelacionamento entre os subsistemas técnico-social e o ambiente nos ajuda a evitar o erro de enfrentarmos situações completamente novas com sistemas organizacionais e estratégias competitivas apropriados a estados de ambiente anteriores. Tendo esta assertiva em mente, apresentaremos um breve quadro his-tórico sobre a dinâmica destas interrelações.

\section{Perspectiva Histórica}

$\mathrm{I}$ niciemos o nosso histórico a partir do trabalho artesanal, predominante até o advento da Revolução Industrial. Esta forma de produção estava fundamentada nas habilidades do artesão, que se utilizava de materiais e ferramentas manuais para a confecção do produto acabado. O artesão era um profissional com habilidades distintivas que realizava praticamente todas as etapas de produção, fornecendo produtos para um mercado geograficamente restrito.

A Revolução Industrial do século XVIII provocou uma profunda mudança no elemento tecnológico da produção. Ela introduziu as máquinas especializadas, em substituição às ferramentas manuais do artesão. Como relatam Piore e Sabel in
PINE II (1994), o uso intensivo das máquinas propiciou dois caminhos distintos: a idéia de que "as máquinas poderiam ampliar as habilidades dos trabalhadores, permitindo que estes incorporassem seus conhecimentos aos mais variados produtos" e a idéia da redução no custo dos produtos por meio da substituição de mão-de-obra qualificada por máquinas. Como afirma PINE II (1994), “durante certo período esses dois caminhos foram menos independentes, devido ao uso simultâneo de trabalhadores habilidosos e mecanização”.

Em 1776, há o surgimento do princípio da divisão do trabalho - especialização de tarefas e fragmentação do trabalho desenvolvido por Adam Smith na obra The 
Wealth of Nations. A associação desta nova forma de organização do trabalho com as máquinas advindas da Revolução Industrial proporcionou um novo modelo de produção - capaz de proporcionar ganhos extraordinários de produtividade do trabalho humano. Entretanto, a industrialização ainda estava incipiente, assim como os mercados consumidores.

As máquinas da Revolução Industrial, os trabalhadores qualificados e o princípio da divisão do trabalho consituíam o paradigma produtivo dos países industrializados Inglaterra, Estados Unidos, França, etc. que predominou até o século XVIII. No início do século XIX, os Estados Unidos que apresentavam um grande crescimento populacional, de mercado interno e de unidades industriais - “quebram” este paradigma por intermédio da introdução de métodos de produção revolucionários, originando o Sistema Americano de Manufatura.

Este sistema, oriundo da busca (pelo governo americano) de maior segurança e confiabilidade dos armamentos militares, apresentava inovações na tecnologia, métodos de gestão e práticas de trabalho. Tal sistema estava baseado no uso de máquinas especializadas para a produção de peças intercambiáveis testadas por padrões de referência, no controle de materiais e da qualidade, mediante um sistema de informações, e na ausência de operadores qualificados para a função de ajuste de peças "unfamiliar organization of work" (BEST, 1990).

O sistema americano, auxiliado pelas facilidades crescentes no transporte de produtos (proliferação das ferrovias), alavancou a emergência dos Estados Unidos como uma potência econômica, já a partir do século XIX. Porém, no início deste século, esse sistema apresentava problemas para "suportar o crescimento de muitas empresas em sua busca de atender à demanda de uma economia [norte-americana] enorme e geograficamente dispersa" (PINE, 1994). Uma evolução do Sistema Americano foi o modelo introduzido por Henry Ford, ou Fordismo, consolidado na década de 20.

Diferentemente do Sistema Americano, que visava qualidade e volume de produção, o Fordismo estava voltado para a eficiência de custos e para a produção em massa de produtos minimamente diversificados, havendo grande congruência entre a estratégia competitiva da empresa (baixos custos) com o seu sistema de produção (em massa). Este sistema baseava-se no uso de mão-de-obra não qualificada alocada a postos de trabalho simples e com boa remuneração, na presença de uma engenharia industrial forte e focalizada no processo, na intercambialidade de peças, no uso de um sistema único de dispositivos de produção e controle máquinas especializadas, fluxo operacional otimizado com a introdução da linha de montagem (que leva o trabalho ao trabalhador), organização hierarquizada e integração vertical.

O crescimento das facilidades de transporte e comunicação, o impacto do Sistema Americano de Manufatura nos países industrializados europeus, o desenvolvimento tecnológico da química e do aço - entre outros fatores materiais - e a evolução do Sistema Ford de produção em massa formaram a base para mudanças no subsistema social das empresas. À medida que vários e mais complexos processos produtivos eram agrupados numa mesma planta e, ao mesmo tempo, as tarefas de manufatura eram divididas em "fatias" muito simples, foi necessário o desenvolvimento de uma nova forma de coordenação e controle. Tratava-se da burocracia, aqui entendida como a hierarquia organizacional composta por partes especializadas - produção, vendas, contabilidade, marketing, recursos humanos, etc. - da função administrativa geral. Como explica BURNS (1963), "todos direitos e poderes em cada nível [hierárquico] derivam do chefe; lealdade, ou 'responsabilidade', é devida a ele; todos benefícios são 'como se fossem' administrados por ele [chefe]”. O grande aumento na proporção de funcionários administrativos em relação aos 
operários de produção na indústria manufatureira dos países industrializados refletia o crescimento da estrutura organizacional das empresas.

Estes “administradores” baseavam-se, fundamentalmente, nos princípios da administração científica, desenvolvidos pelo engenheiro Frederick W. Taylor. O Taylorismo envolvia o estudo minucioso de tempos e métodos, a divisão clara entre o planejamento - a cargo dos administradores - e a execução das atividades (já fragmentadas e simples) pelos operários com a conseqüente redução das habilidades profissionais da mão-de-obra.

O sistema de produção introduzido por Ford agiu como um catalisador positivo para a consolidação da hegemonia econômica norte-americana na década de 60 - iniciada anteriormente com o Sistema Americano de Manufatura. Esse crescimento econômico provocou a rápida difusão do modelo Fordista para os demais países industrializados - que o adotaram acriticamente criando-se um novo paradigma de produção e organização do trabalho.

O Fordismo desenvolveu-se num ambiente relativamente estável, com mercados pouco exigentes e em franca expansão. Entretanto, nos anos 70, o ambiente internacional de negócios começou a passar por profundas transformações. O mercado passou de comprador a vendedor, com foco crescente na qualidade. Nesse contexto, o Japão começa a emergir como o novo padrão de referência internacional, uma vez que suas empresas já vinham adotando estratégias competitivas, adequadas para o novo ambiente, e desenvolvendo inovações nas formas de organização da produção e do trabalho que suportassem as suas estratégias.

CORIAT (1993) argumenta que o conjunto de inovações organizacionais japonesas originou uma nova escola de gestão da produção, muito mais adaptada às condições comtemporâneas de competição, nas quais "diferenciação e qualidade têm um lugar especial”. Este novo ambiente ditava restrições sérias aos ganhos de produtividade advindos da produção em massa e economias de escala. Era necessário produzir lotes pequenos, com qualidade e a um custo competitivo.

A partir da II Guerra Mundial, Taiichi Ohno - engenheiro-chefe das fábricas de automóveis Toyota - desenvolve uma série de técnicas e metodologias de trabalho para a obtenção de ganhos de produtividade na produção de lotes pequenos e variados. Uma de suas invenções revolucionárias foi o Justin-Time (JIT), que, por meio da gestão por estoques, "tensiona” a fábrica, ressaltando pontos para a racionalização do trabalho.

O Ohnismo - termo usado por Coriat para designar a nova escola japonesa em gestão da produção - , diferentemente do Fordismo clássico, baseou-se na polivalência e na plurifuncionalidade dos homens e das máquinas em conjunto com a "liberalização”, "flexibilidade interna” e "autonomação" (responsabilidade pela qualidade dos produtos nos próprios postos de trabalho) da produção. Desta forma, Ohno introduz o importante princípio do trabalho baseado em tarefas múltiplas, mais agradáveis e com padrões (de tempo e de trabalho) flexíveis, configurando um processo de aprendizagem.

Outros dois aspectos extremamente importantes do "modelo" japonês apresentado por AOKI (1990) são a coordenação horizontal entre as unidades operacionais, baseando-se no uso efetivo (geralmente informal) de informações emergentes, e o compartilhamento destas informações (aprendizagem). Este modo interno de operação está bastante interrelacionado com o sistema japonês de emprego - hierarquia por ranks, competição entre os funcionários como mecanismo de estímulo, emprego vitalício, etc.. Como ilustra AOKI (1990), tanto o modo de operação quanto a estrutura dos empregos estão interrelacionados com a natureza do sistema administrativo e o comportamento das empresas (estrutura de decisão interna, esquema de financiamento pelos bancos, interdependência das empresas, comprometimento mútuo entre as 
empresas e os funcionários, etc.).

Baseando-se na Teoria Geral dos Sistemas que afirma que todo sistema está contido num outro sistema de ordem superior, FRUIN (1992) amplia o "modelo" japonês para abranger a sistemática do relacionamento interempresas (fábricas focalizadas, firmas e redes interfirmas). Portanto, podemos considerar o método de produção japonês como um sistema dinâmico e integrado. Em outras palavras, o Ohnismo está inserido na "era dos sistemas", dentro do conceito de ACKOFF (1972).

É importante observar que apesar das diferenças, o Ohnismo não destrói o Fordismo, mas o redefine dentro de uma lógica sistêmica - por exemplo, ambos os sistemas estão fortemente apoiados nos protocolos de tempos e métodos de Taylor e na busca intensa da redução dos desperdícios; entretanto, no sistema japonês, os "padrões são reagregados e moduláveis”, configurando um processo de aprendizagem. Valendonos dos conceitos apresentados por BURNS (1963), podemos afirmar que o Fordismo está mais voltado para um esquema de administração "mecanístico" - especialização funcional, interação e comunicação por meio da hierarquia vertical, definição clara e precisa dos direitos e obrigações dos funcionários, comportamento "guiado" pelos superiores, etc. -, que é mais adequado a condições relativamente estáveis.

Já o Ohnismo aproxima-se bastante do esquema administrativo "organísmico" comunicação preferencialmente lateral, aprendizagem na forma de compartilhamento de experiências e informações, visão de conjunto da empresa, contínua redefinição de tarefas individuais por meio de interação com os pares, autoridade por meio do conhecimento, etc. -, mais voltado para situações dinâmicas (como os mercados crescentemente voláteis e instáveis).

Desta discussão inicial, podemos derivar uma conclusão fundamental: em todos os casos em que um modelo de produção teve êxito, tornando-se um paradigma, houve o alinhamento estratégico dos subsistemas técnico e social das empresas com o ambiente externo.

\section{As Mudanças dos Anos 90}

$\mathrm{E}$ stamos vivendo um "novo tempo" no mundo dos negócios. O ambiente contemporâneo está passando por profundas alterações estruturais. A evolução nas relações de poder entre clientes - cada vez mais dominantes - e produtores, o acirramento da competição empresarial dentro de um contexto transnacional, a explosão tecnológica - em especial, da tecnologia baseada na microeletrônica -, a facilidade de transferência internacional de investimentos para empresas e mercados que os remuneram melhor e a proliferação da oferta de novos e mais complexos produtos e serviços, cujos ciclos de vida são progressivamente mais curtos, são as principais forças que estão alterando o ambiente de negócios. Além dessas forças, exercem grande influência sobre o ambiente os fatores políticos, econômicos e legais (JOHANSSON et al., 1993).

Tais forças vêm afetando a indústria brasileira na medida em que se busca a sua integração à economia mundial. Essa integração é estimulada (ou pressionada...) por meio de mecanismos como a Política Industrial e de Comércio Exterior (PICE) lançada pelo Governo Federal em 1990, alterando a estratégia de fabricação local, em substituição às importações, para a estratégia de exposição do mercado nacional à concorrência internacional -, a redução de subsídios governamentais em determinados setores, o Código de Defesa do Consumidor, registro ISO 9000, o Programa Brasileiro de Qualidade e Produtividade (PBQP), a desregulamentação de mercados, as pressões contra monopólios e a própria recessão 
econômica (BORGES, 1993; CARVALHO, 1994).

Este novo ambiente concorrencial, agressivo e em mutação constante, impõe fortes pressões às empresas, alterando significativamente as bases da competitividade. Visando a prosperidade ou mesmo a sobrevivência, as empresas procuram responder a essas pressões por meio da melhoria da qualidade e do atendimento ao cliente, do enxugamento dos tempos de ciclos de processos, da redução de preços ao cliente (pela compressão das margens de lucro e/ou redução de custos), da criação de produtos e serviços que atendam, antes dos concorrentes, necessidades de clientes ainda não detectadas - nem mesmo pelos próprios clientes -, da melhoria da flexibilidade e da melhor capacitação tecnológica.

Visando o aumento da competitividade neste novo cenário, muitas empresas, especialmente as ocidentais, vêm se reestruturando - reduzindo a magnitude de suas operações e da sua força de trabalho (downsizing) - e adotando elementos do "modelo" japonês como just-in-time e total quality management.

Também um outro conceito vem sendo largamente difundido e empregado pelas empresas em todo o mundo. Trata-se da reengenharia de processos, que segundo Michael Hammer - considerado o seu precursor nos moldes atuais - é definida como "o uso do poder da moderna tecnologia de informação para reprojetar radicalmente os processos empresariais, visando atingir níveis dramáticos de melhoria em seus desempenhos" (HAMMER, 1990). Mais recentemente, HAMMER \& CHAMPY (1993) refinaram a definição anterior: "reengenharia é o questionamento dos fundamentos básicos e reprojeto radical dos processos empresariais para alcançar melhorias dramáticas em medidas contemporâneas de desempenho, tais como custo, qualidade, atendimento ao cliente e velocidade".'

Embora existam algumas discussões acerca da obrigatoriedade do uso da TI na reengenharia de processos e sobre os ganhos de produtividade com ela obtidos, parecenos que o papel que a TI vem desempenhando no mundo moderno dos negócios é fundamental, pois abre um novo horizonte para inovações nos subsistemas técnico e social das empresas.

Entretanto, esse potencial tecnológico não tem sido aproveitado na sua plenitude. Este aspecto é abordado a seguir.

\section{A Crise da Produtividade}

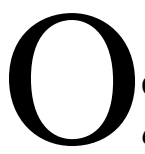

universo da TI é muito vasto e está em rápida expansão. O poder de um chip processador de um computador pessoal dobra a cada dezoito meses (BUSI-NESS WEEK, 17/outubro/1994). Segundo o jornal The European do dia 12 de agosto de 1994 o mercado de informática vem crescendo, no âmbito mundial, a uma taxa aproximada de $6.7 \%$ ao ano desde 1988.

Porém, vários estudos realizados em grandes empresas, particularmente nas americanas, demonstram que apesar dos grandes investimentos em TI na década de 80, a produtividade do trabalho de "colarinho branco" (white collar) - intimamente ligado com informações - tem permanecido praticamente estagnada (INFORMÁTICA EXAME, 1994; DAVENPORT, 1993; THUROW, 1993). Em contrapartida, durante esse mesmo período, a produtividade do trabalho diretamente ligado à manufatura (blue collar) cresceu aproximadamente 30\% nos Estados Unidos (THUROW, 1993).

Uma possível explicação para essa diferença reside no uso da moderna TI representada, basicamente, pela automação eletrônica - para alterar os processos produtivos e, em grande parte, a natureza e a organização do trabalho (blue collar). De forma distinta, no trabalho de "colarinho branco" - que envolve considerável 
intervenção humana, é geralmente pouco visível, pouco documentado e complexo -, a TI foi usada para acelerar as rotinas e procedimentos manuais.

Essa é também a tese central de HAMMER (1990) que, referindo-se aos resultados pouco alentadores da TI, afirma que "[este fato ocorre] principalmente por-que as empresas tendem a usar a tecnologia para mecanizar velhas maneiras de realizar os negócios. Elas [as empresas] deixam os processos existentes intactos e usam o computador para realizá-los mais rápido”. Complementamos essa tese afirmando que esses processos continuam, quase que na totalidade, sendo realizados pelos mesmos profissionais e baseados nos mesmos princípios anteriores à TI.

Uma possível alternativa para este problema é a visualização de inovações da TI sob um prisma sistêmico, envolvendo os vários elementos da organização. A seguir, discutiremos esta proposição.

\section{A Lógica Sistêmica da TI}

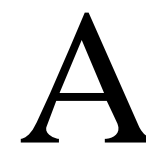

s influências do uso "correto" da TI nas empresas podem ser visualizadas por meio de uma lógica sistêmica, como sugerido no item anterior. A TI oferece a infra-estrutura técnica para a concepção e a implementação de processos empresariais completamente novos, supos-tamente mais eficazes e eficientes. Como os processos são os meios pelos quais as pessoas realizam trabalho, inovações nos processos certamente afetam a natureza do trabalho, o perfil profissional, a divisão de poder na organização e o seu sistema de comunicação interno - elementos constituíntes da estrutura organizacional. Em havendo tais alterações estruturais, serão necessários ajustes no gerenciamento dos recursos humanos da empresa - nível de habilidades, recrutamento, compensação, carreira, sis-tema de avaliação de desempenho, etc.. Por sua vez, as políticas e práticas na área de recursos humanos exercem uma influência direta sobre os valores e credos dos indivíduos da companhia. Assim sendo, tais valores e credos - cultura da organização - são os elementos comportamentais que suportam as inovações na forma de realização do trabalho.

Esta lógica sistêmica não está completa, porém nos permite entender o elo existente entre os vários elementos da empresa diante de inovações tecnológicas - em especial, na área da TI. A falta de entendimento e equacionamento integrado desses elos é, muito freqüentemente, a causa do fracasso dos projetos de reestruturação industrial.

Até o presente momento, apresentamos um quadro conceitual que subsidia a compreensão das profundas alterações das características do trabalho humano enfrentadas pelas empresas e profissionais neste final de século. A seguir, algumas dessas alterações são analisadas à luz das inovações da TI.

\section{A TI e o Novo Trabalho}

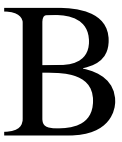

aseando-nos na classificação de DAVENPORT (1993), apresentaremos e discutiremos a seguir as capacidades da TI - combinação lógica de sistemas de informações, redes e telecomunicações - e seus impactos no trabalho humano, particularmente, no trabalho de "colarinho branco".

\section{Capacidade de Automação}

Inicialmente empregada nas atividades diretamente ligadas à manufatura, a TI pode ser utilizada para reduzir ou eliminar o trabalho humano de determinados processos 
empresariais. Tarefas repetitivas e que não exigem criatividade podem ser automatizadas, trazendo, certamente, vantagens em tempo de execução e em custos. A automa- ção dos processos empresariais afeta mais diretamente os funcionários administrativos que executam tarefas rotineiras.

\section{Capacidade de Fornecimento de Informação.}

A TI oferece a possibilidade de informar instantânea e continuamente as pessoas (ou máquinas) com dados e variáveis importantes sobre o desempenho de um certo processo. Baseando-se nesses dados, ações para o aumento da qualidade, da produtividade, ou de ambas, podem ser implementadas mais eficazmente pelos próprios agentes do processo. Dessa forma, maiores habilidades analíticas e técnicas, bons conhecimentos em metodologias e ferramentas de análise e de melhoria de processos e sistema de gerenciamento alinhado a esses objetivos são pré-requisitos - não exaustivos - para que se obtenham os benefícios desta capacidade da TI.

\section{Capacidade de Seqüenciamento}

Por meio do compartilhamento estruturado de informações oferecido pelos recursos da TI, é possível otimizar a seqüência de atividades de um processo, realizando várias atividades em paralelo. Esta otimização visa reduzir os tempos de ciclo e os recursos utilizados, assim como melhorar a qualidade nas saídas dos processo. Este é o conceito básico da Engenharia Simultânea, largamente empregada pelas empresas no desenvolvimento de novos produtos. Dentro deste contexto, o trabalho passa a ser realizado de forma mais cooperativa e integrada, havendo o compartilhamento de informações e experiências por todos os profissonais envolvidos no processo. Assim sendo, a TI facilita a aprendizagem organizacional nos moldes de GARVIN (1993). Entretanto, o novo processo exige profissionais com boa capacidade de comunicação e de trabalho em grupo, além de habilidades em ferramentas tecnológicas como CAD/CAM/CAE/ CIM e groupware.

\section{Capacidade de Rastreamento}

Sistemas computacionais aliados às telecomunicações vêm alterando os processos que necessitam de informações posicionais e geográficas. Com essas tecnologias, o rastreamento de objetos e pessoas é bastante preciso, permitindo que decisões operacionais mais efetivas sejam tomadas e comunicadas imediatamente. Desta forma, afirmam HAMMER \& CHAMPY (1993), “não é necessária tanta redundância em pessoal, equipamentos e materiais para cobrir os atrasos inerentes para localizar e redirecionar objetos e pessoas em trânsito". Entretanto, maior habilidade profissional é requerida das pessoas envolvidas nesse tipo de processo, pois são elas que irão interagir com a tecnologia de rastreamento durante a realização de suas atividades.

\section{Capacidade de Análise.}

A TI oferece um conjunto de sofisticadas ferramentas que suportam os processos de análise e tomada de decisões. As bases de conhecimento, que colecionam e indexam uma grande quantidade de dados e informações, permitem que as pessoas busquem as informações desejadas de maneira muito mais rápida e efetiva. Também os sistemas 
especialistas fornecem o expertise de peritos em certos campos do conhecimento a pessoas generalistas. Como corolário direto, há a mudança do perfil profissional requerido: maior preparo educacional, novas posturas (como a adoção do "senso de propriedade" e “delegação de autoridade”), formação mais genérica, etc.. Assim, a capacidade de análise da TI ajuda as pessoas na tomada de decisões mais rápidas e mais próximas da realização do trabalho e, possivelmente, do cliente final; dessa forma, a redução dos níveis hierárquicos nas empresas é uma conseqüência natural da nova maneira de organizar e realizar o trabalho e não um reflexo contingencial de redução de custos.

\section{Capacidade Geográfica}

Um dos benefícios-chave da TI é a sua capacidade de cruzar fronteiras geográficas instantaneamente. Redes de telecomunicações conectam grandes empresas, seus fornecedores e clientes sediados em diferentes localidades, permitindo que os processos empresariais sejam tratados de forma global, freqüentemente no âmbito da corporação (e não mais regional e descentralizado). A facilidade de comunicação transnacional oferece novas oportunidades de otimizações para as empresas e suporta a crescente globalização da economia. Com este embasamento, a comunicação internacional exige dos profissionais maiores conhecimentos em línguas e culturas estrangeiras.

\section{Capacidade de Integração}

O uso de bancos de dados compartilhados, em conjunto com os sistemas especialistas, permitem a "reintegração" do trabalho - anteriormente separado pelo princípio da especialização -, ou seja, a realização de todo (ou grande parte) do processo pelas mesmas pessoas. A "reintegração" exige dos profissionais maior visão global do processo e habilidades multidisciplinares, além de novas posturas com relação ao trabalho fornecido aos seus clientes.

\section{Capacidade de Difusão Intelectual}

Os bancos de dados, as redes de telecomunicações e os softwares aplicativos oferecem uma extraordinária oportunidade para a discussão de idéias, o compartilhamento de experiências e a difusão de conhecimentos. A adoção de instâncias intelectuais de discussão contribui significativamente para o aprendizado global da organização. Nas grandes e modernas companhias informatizadas que se utilizam desta facilidade, os funcionários estão constantemente "aprendendo uns com os outros", contribuindo para o aumento de suas competências técnicas e gerenciais. Nesse ambiente, a tecnologia "propulsiona" o auto-aprimoramento.

\section{Capacidade de Conexão}

A TI pode ser empregada para a conexão direta de interlocutores, sem a intermediação humana. Os variados tipos de redes de comunicação, o processamento de imagens e documentos, o E-mail, redes (por exemplo, Internet) e a computação móvel contribuem para a rápida troca de informações direta- mente entre as partes interessadas de um determinado processo. Esta capacidade da TI afeta diretamente a gerência intermediária tradicional das hierarquias burocráticas, cuja função principal é a transmissão bidirecional de informações. São crescentes os funcionários que querem tomar as 
próprias decisões em empresas que também querem conferir-lhes tal autonomia, sem a “benção” de ocupantes dos níveis hierárquicos intermediários.

\section{Conclusões}

$\mathrm{I}$

niciamos o nosso texto caracterizando a empresa como um sistema sócio-técnico aberto, ou seja, que interage com o ambiente externo. Uma vez que o ambiente externo influencia os subsistemas e estratégias da empresa, o histórico da evolução dos modelos de produção nos ajuda a entender o interrelacionamento entre estes elementos - ambiente, estratégia, subsistema social e subsistema técnico.

Assim sendo, apresentamos um quadro histórico sobre a dinâmica destas interrelações e derivamos uma conclusão bastante importante: em todos os casos em que um modelo de produção teve êxito, tornando-se um paradigma, houve o alinhamento estratégico dos subsistemas técnico e social das empresas com $o$ ambiente externo.

A partir dessa retrospectiva, discutimos os anos 90 e o papel fundamental que a TI vem desempenhando nas empresas do mundo moderno, abrindo um novo horizonte para as inovações organizacionais, e não apenas para a automação pura e simples dos processos empresariais existentes nas companhias.

A partir de inovações na TI, exercitamos uma lógica sistêmica abrangendo vários elementos da empresa. Desse exercício, podemos afirmar que o entendimento e o equacionamento integrado de elementos tais como, processos, emprego, habilidades profissionais, estrutura organizacional, sistema de gerenciamento, cultura e tecnologia, são condições necessárias para o sucesso dos projetos de reestruturação industrial.

Nesta nova revolução industrial a TI assume um papel similar ao das máquinas especializadas do século XVIII. Assim, a partir da perspectiva histórica e da lógica apresentada neste trabalho, visualizamos as recentes e profundas alterações do trabalho humano como "alinhamentos" do subsistema social às inovações tecnológicas, às direções estratégicas e ao ambiente exterior. É sob esta perspectiva que abordagens do tipo "reengenharia" devem ser analisadas e empreendidas.

Entretanto, ainda não temos uma visão muito clara acerca dos próximos paradigmas de produção e de organização do trabalho. Porém, um ponto nos parece patente: independentemente do "novo modelo" de produção, a TI está sendo a "mola propulsora” dessa transição de paradigmas.

\section{Referências Bibliográficas}

ACKOFF, R. Redesigning the future. McMillan, New York, 1972.

AOKI, M.: "Toward an economic model of the Japanese firm". Journal of Economic Literature, v. 28, p. 1-27, March 1990.

BEST, M.: "The new competition: institutions of industrial restructuring”. Harvard University Press, Cambridge, Mass., 1990.

BIAZZI Jr, F.: "O trabalho e as organizações na perspectiva sócio-técnica”. Revista de Administração de Empresas, v. 34, n. 1, p. 30-37, 1994.
BORGES, P.C.S.: Metodologia para aperfeiçoamento de processos empresariais: uma abordagem alternativa. Dissertação de Mestrado, Instituto de Matemática, Estatística e Ciência da Computação, Universidade de Campinas, SP, (153 p.), 1993.

BURNS, T.: "Industry in a new age". New Society, p. 17-20, 31 January 1963.

BUSINESS WEEK: "The new world of work". Business Week, p. 42-49, October 17, 1994. 
CARVALHO, R.Q.: "Capacitação tecnológica limitada e uso do trabalho na indústria brasileira”. São Paulo em Perspectiva, v. 8, n. 1, p. 133-143, 1994.

CHURCHMAN, C.W.: Introdução à teoria dos sistemas. Editora Vozes, Petrópolis, RJ, 1972.

CORIAT, B.: "Ohno e a escola japonesa de gestão da produção: um ponto de vista de conjunto" in HIRATA, H. S. (org.): Sobre o “modelo" japonês. EDUSP, São Paulo, (p. 79-91), 1993,

DAVENPORT, T.H.: Process innovation: reengineering work through information technology. Harvard Business School Press, Boston, Mass., 1993.

FRUIN, W.M.: The Japanese enterprise system: competitive strategies and cooperative structures. Clarendon Press, Oxford, 1992.

GARVIN, D.A.: "Building a learning organization”. Harvard Business Review, p. 78-91, July-August 1993.

HAMMER, M.: "Reengineering work: don't automate, obliterate". Harvard Business Review, p. 104-112, July-August 1990.
HAMMER, M. \& CHAMPY, J.: Reengineering the corporation: a manifest for business revolution. Harper Business, New York, 1993.

INFORMÁTICA EXAME: "É hora de recomeçar”. Informática Exame, p. 64-71, março 1994.

JOHANSSON, H.J., McHUGH, P., PENDLEBURY, A.J. \& WHEELER III, W.A.: Business process reengineering: breakpoint strategies for market dominance. John Wiley \& Sons, West Sussex, 1993.

PINE II, B.J.: Personalizando produtos $e$ serviços - customização maciça. Makron Books, São Paulo, 1994.

THUROW, L.C.: "Productivity" . In: CHRISTOPHER, W. F. (ed.) \& THOR, C. G. (ed). Handbook for Productivity Measurement and Improvement. Productivity Press, Massachusetts, 1993.

\section{IMPACTS OF INFORMATION TECHNOLOGY ON "WHITE COLLAR" WORK}

\section{Abstract}

Huge investiments in information technology (IT) have been directed to business process improvements. Generally, such investments are limited to the sole automation of already existing processes, which continue to be performed according to the same rules and by the same professionals prior to IT. A consequence of this kind of automation is the low productivity increase in white collar work. An alternative to this problem is business process reengineering, which, via the creative use of IT, strives to establish much more effective ways of performing work. However, very often such new ways affect the professional skills and the nature of the work. This paper discusses the impacts of IT on white collar work.

\section{Key-words: information technology, white collar work, work organization, business} process, reengineering. 